\title{
Direct Contact between Sympathetic Neurons and Rat Cardiac Myocytes In Vitro Increases Expression of Functional Calcium Channels
}

\author{
Shunichi Ogawa, Joey V. Barnett, Luyi Sen, Jonas B. Galper, Thomas W. Smith, and James D. Marsh \\ Department of Medicine, Brigham and Women's Hospital and Harvard Medical School, Boston, Massachusetts 02115
}

\begin{abstract}
To test the hypothesis that direct contact between sympathetic neurons and myocytes regulates expression and function of cardiac Ca channels, we prepared cultures of neonatal rat ventricular myocytes with and without sympathetic ganglia. Contractile properties of myocytes were assessed by an optical-video system. Contractility-pCa curves showed a $60 \%$ greater increase in contractility for innervated myocytes compared with control cells at $6.3 \mathrm{mM}[\mathrm{Ca}]_{0}(n=8, P<0.05)$. Cells grown in medium conditioned by growth of ganglia and myocytes were indistinguishable physiologically from control cells. [Bay $K$ 8644]contractility curves revealed a $60 \pm 10 \%$ enhancement of the contractility response at $10^{-6} \mathrm{M}$ for innervated cells compared with control cells. The increased response to Bay $\mathrm{K} 8644$ was not blocked by $\alpha$ - or $\beta$-adrenergic antagonists. Moreover, increased efficacy of Bay K 8644 was maintained for at least $24 \mathrm{~h}$ after denervation produced by removal of ganglia from the culture. Dihydropyridine binding sites were assessed with the $L$ channel-specific radioligand ${ }^{3}[\mathrm{H}] \mathrm{PN} 200-110$. PN200-110 binding sites were increased by innervation $(51 \pm 5$ to $108 \pm 20 \mathrm{fmol} / \mathrm{mg}$ protein, $P<0.01$ ), with no change in $K_{\mathrm{D}}$. Peak current-voltage curves were determined by whole-cell voltage clamp techniques for myocytes contacted by a neuron, control myocytes, and myocytes grown in conditioned medium. Current density of $\mathbf{L}$ type Ca channels was significantly higher in innervated myocytes $(10.5 \pm 0.4 \mathrm{pA} / \mathrm{pF}, n=5)$ than in control myocytes $(5.9 \pm 0.3 \mathrm{pA} / \mathrm{pF}, n=8, P<0.01)$ or myocytes grown in conditioned medium $(6.2 \pm 0.2 \mathrm{pA} / \mathrm{pF}, n=10, P<0.01)$. Thus, physical contact between a sympathetic neuron and previously uninnervated neonatal rat ventricular myocytes increases expression of functional L-type calcium channels as judged by contractile responses to $\mathrm{Ca}_{0}$ and Bay $K$ 8644, as well as by electrophysiological and radioligand binding properties. ( $J$. Clin. Invest. 1992. 89:1085-1093.) Key words: cardiomyocyte • cell culture $\bullet$ dihydropyridine $\bullet$ ion channel
\end{abstract}

\section{Introduction}

Cardiac L-type calcium channels play a crucial role in excitation-contraction coupling. Modulation of L-type calcium channel expression may influence the inotropic state of the heart. However, little is known about molecular and cellular

Address reprint requests to Dr. Marsh, Cardiovascular Division, Brigham and Women's Hospital, 75 Francis Street, Boston, MA 02115.

Received for publication 22 February 1991 and in revised form 22 October 1991.

J. Clin. Invest.

(c) The American Society for Clinical Investigation, Inc.

$0021-9738 / 92 / 04 / 1085 / 09 \$ 2.00$

Volume 89, April 1992, 1085-1093 mechanisms that regulate the abundance of calcium channels. The L-type calcium channel is a heteromeric protein with $\alpha_{1}$, $\alpha_{2}, \beta, \gamma$, and $\delta$ subunits (1). The $\alpha_{1}$ subunit is believed to provide the pore for $\mathrm{Ca}^{2+}$ entry and contains the binding site for dihydropyridine calcium channel antagonists and agonists. Recently, Barnett et al. (2) developed a method for the study of the effect of co-culture of ciliary ganglia and embryonic chick heart cells on the parasympathetic response of the heart. To gain an enhanced understanding of fundamental mechanisms that regulate the number of cardiac calcium channels present on a myocyte, we adapted this method to test the hypotheses that the presence of sympathetic neurons increases abundance of L-type calcium channels in myocytes in vitro, and that an increase in calcium channel number is physiologically important.

It is clear that the function of existing calcium channels can be modulated by neurotransmitters and hormones (3). Agonist binding to $\beta$-adrenergic receptors leads to phosphorylation of calcium channels and an increase in calcium channel current $(3,4)$. However, the effect of the process of sympathetic innervation on the expression of the L-type calcium channel $\alpha_{1}$ subunit gene product is unknown. Several lines of evidence suggest that cation channel expression might be altered by innervation. For example, Marsh and Allen (5) found that during ontogeny of the avian heart, shortly after ingrowth of sympathetic nerves, there was a marked increase in number of dihydropyridine (DHP) ${ }^{1}$ binding sites. Offord and Catterall (6) found that electrical activity and cyclic AMP can regulate mRNA-encoding sodium channel $\alpha$ subunits in muscle cells.

The in vitro model system for co-culture of sympathetic ganglia and ventricular myocytes used in this study permitted selection of the cell type under study and examination of the role of cell contact and denervation in regulation of calcium channel expression. Our findings demonstrate that direct contact with myocytes by sympathetic neurons does lead to an increase in expression of functional L-type calcium channels.

\section{Methods}

Culture of neonatal rat ventricular myocytes. Neonatal rats ( $1 \mathrm{~d}$ old $)$ were deeply anesthetized with ether and killed by decapitation. Hearts were removed, trimmed of connective tissue, and minced into fragments of $\sim 3 \mathrm{~mm}^{3}$. Myocytes were dissociated by cyclic trypsinization $(0.25 \%$ trypsin solution) in Hanks' balanced salt solution. After centrifugation at $800 \mathrm{~g}$ for $5 \mathrm{~min}$, cells were suspended in Dulbecco's modified essential medium containing $7 \%$ fetal calf serum (FCS) and antibiotics (gentamicin, streptomycin, penicillin) and were preplated (1 $\times 10^{6}$ cells $/ \mathrm{ml}, 50-\mathrm{mm}$ culture dishes) for $60 \mathrm{~min}$ in a humidified $5 \%$ $\mathrm{CO}_{2} / 95 \%$ air atmosphere at $37^{\circ} \mathrm{C}$. Cells were plated at $1 \times 10^{6}$ cells $/ \mathrm{ml}$

1. Abbreviations used in this paper: DHP, dihydropyridine; $I-V$, current-voltage. 
in $35-\mathrm{mm}$ culture dishes on $12-\mathrm{mm}$ circular coverslips in the same culture medium. Cell cultures were maintained in a humidified $5 \%$ $\mathrm{CO}_{2} / 95 \%$ air atmosphere $\left(37^{\circ} \mathrm{C}\right)$.

Co-culture of neonatal rat supracervical sympathetic ganglia with ventricular myocytes. Cultures were prepared by a modification of the method of Atkins and Marvin (7) and by a modification of the method of Barnett and Galper (2). After sacrifice of 1-d-old neonatal rats, supracervical sympathetic ganglia were removed aseptically and placed in culture dishes that contained Hanks' salt solution. The ganglia were dissected free from associated tissue and cut into $1-\mathrm{mm}^{3}$ fragments. The ganglia were plated on 12-mm circular, collagen-coated (type I, from adult rat tail tendons) coverslips in 35-mm culture dishes. Ganglia were incubated with a small volume of culture medium in a humidified $5 \% \mathrm{CO}_{2} / 95 \%$ air atmosphere at $37^{\circ} \mathrm{C}$ for $2-3 \mathrm{~h}$ during which time the ganglia attached to the substrate. At this time freshly dissociated rat ventricular myocytes $\left(1 \times 10^{6}\right.$ cells $\left./ \mathrm{ml}\right)$ were added to the culture dishes containing ganglia. Myocyte-ganglion co-cultures were incubated as above.

Assessment of neuroeffector transmission. Neuroeffector transmission of sympathetic neurons was assessed physiologically by direct electrode stimulation of ganglia with axons terminating on ventricular myocytes. A platinum electrode was placed directly on a ganglion and short unipolar pulses (3-4 Hz, $3 \mathrm{~ms}$ in duration) were delivered. Myocytes were continuously superfused with Hepes-buffered solution containing (mM): Hepes, 5.0; $\mathrm{CaCl}_{2}, 0.9 ; \mathrm{KCl}, 4.0 ; \mathrm{NaCl}, 140 ; \mathrm{MgCl}_{2}, 0.5$. The frequency of contractions of the myocytes contacted by axons was recorded by an optical video system as previously described in detail (8), and a signal indicating electrical stimulation was recorded concurrently.

Measurement of contractile responsiveness of myocytes. Contractile responses to $\mathrm{Ca}^{2+}$ and ( \pm )Bay $\mathrm{K} 8644$ were measured after 3 or $4 \mathrm{~d}$ in culture. The cells were electrically stimulated $(2.5 \mathrm{~Hz})$, and were stabilized for at least $15 \mathrm{~min}$ before exposure to graded, increasing concentrations of $\mathrm{Ca}^{2+}(0.3,0.6,0.9,1.8,3.6,5.4,6.3 \mathrm{mM})$, or $( \pm)$ Bay K 8644 $\left(10^{-9}\right.$ to $\left.10^{-6} \mathrm{M}\right)$. For each cell, contractile response to Bay $\mathrm{K} 8644$ was assessed in Hepes buffer containing the $\mathrm{EC}_{50}$ concentration of $\mathrm{Ca}^{2+}$. Maximal amplitude of contraction was measured for each cell using the $\mathrm{EC}_{100}$ concentration of $\mathrm{Ca}^{2+}$. Medium was superfused at $1.0 \mathrm{ml} / \mathrm{min}$. The analog voltage output from the video motion detector was filtered at $6 \mathrm{~Hz}$ and was calibrated to indicate actual microns of motion. Amplitude and velocity of contraction was recorded on a strip chart recorder. Contractility measurements were made on only one cell per coverslip. Changes in amplitude and velocity of cell motion were used to quantitate the effects of interventions on cell contractile properties. The methods used have been established and extensively validated in this laboratory $(8,9)$. While amplitude and velocity of contraction of single myocytes are recorded as surrogates for actual force of contraction, amplitude and velocity of contraction for isotonic contraction of lightly loaded muscle closely tracks developed force $(8,10)$, and therefore serve as useful indices of a cell inotropic state.

PN200-110 binding assay. Ligand binding experiments using $\left[{ }^{3} \mathrm{H}\right](+)-\mathrm{PN} 200-110$ were conducted on membranes prepared from ventricular myocytes or myocytes grown in co-culture with ganglia after 3 $\mathrm{d}$ of growth. For myocytes grown in co-culture, ganglia were removed aseptically by microscopic dissection after $3 \mathrm{~d}$ of growth; $8 \mathrm{~h}$ later denervated cells were studied. Before ligand binding experiments, culture medium was aspirated, and cells were washed twice in buffer $\mathrm{A}$ [containing (mM): Tris, 20; EDTA-Na, 2.0; EGTA, 0.1; sucrose, 250 (pH 7.0)], and scraped from culture dishes into buffer $A$. The cells were frozen and thawed twice followed by 12 strokes of Dounce homogenization using a tight-fitting pestle. The crude homogenate was centrifuged at $19,000 \mathrm{~g}$ for $\mathbf{4 0} \mathrm{min}$ and the resulting membranes were resuspended in Hepes buffer containing the $\mathrm{EC}_{50}$ concentration of $\mathrm{Ca}^{2+}$, identical to the buffer for contractility experiments. The entire preparation was at $4^{\circ} \mathrm{C} .400 \mu \mathrm{l}$ of membrane suspension was added to glass tubes containing graded concentrations of $\left[{ }^{3} \mathrm{H}\right](+)-\mathrm{PN} 200-110(50-1,500 \mathrm{pM})$ with or without $50 \mu \mathrm{l}$ of $10^{-5} \mathrm{M}$ unlabeled (+)-PN200-1 10 to define nonspecific binding. Protein concentration was $0.15-0.8 \mathrm{mg} / \mathrm{ml}$. Incubation was at $37^{\circ} \mathrm{C}$ for $30 \mathrm{~min}(5)$. Binding was terminated by vacuum filtration using a cell harvester (Brandel Co., Gaithersburg, MD). Filters (GF/B, Whatman, Inc., Clifton, NJ) were dried under high vacuum and were placed in scintillation counting vials for assessment of bound $\left[{ }^{3} \mathrm{H}\right](+)-\mathrm{PN} 200-110$.

Equilibrium binding data were analyzed using the interactive nonlinear least-squares method of Munson and Rodbard (a modification of the LIGAND program) with a MicroVax computer (Digital Equipment Corp., Maynard, MA) as described (11). This program utilizes initial estimates for agonist and antagonist $K_{\mathrm{D}}$ values, maximum binding $\left(B_{\max }\right)$, and nonspecific binding for each ligand to solve a series of linear equations that completely describe an equilibrium binding isotherm.

Each point was assayed in triplicate, and each individual binding curve was replicated at least four times. All equilibrium dissociation constants are expressed as the mean \pm SEM.

Whole-cell patch-clamp. Calcium currents were obtained using the whole cell patch clamp technique. Currents were recorded with an Axopatch-IC patch clamp amplifier (Axon Instruments, Inc., Foster City, CA; cutoff frequency $1 \mathrm{KHz}$ ) and analyzed on an IBM-AT computer using the pCLAMP program. Standard procedures were used for the patch clamp recordings and isolation of calcium channel currents. Whole cell recordings were obtained with the external solution containing (mM): $20 \mathrm{Ba}$ acetate; 135 tetraethyl ammonium aspartate; 10 Hepes; $30 \mu \mathrm{M}$ tetrodotoxin; $\mathrm{pH}$ 7.5. The internal solution contained 135 Cs aspartate; 10 EGTA; 10 Hepes; 4 ATP; $5 \mathrm{MgCl}_{2}$; $\mathrm{pH}$ 7.5. The average cell capacitance was $53 \pm 10 \mathrm{pF}$ in innerverted cells and $49 \pm 13$ $\mathrm{pF}$ in control cells. Resting membrane potential was typically $-75 \mathrm{mV}$ and no consistent difference was noted between noninnervated and innervated myocytes. Series resistance compensation was $0.55 \mathrm{M} \Omega$ out of a total pipette resistance of $0.65 \mathrm{M} \Omega$. Stimulation frequency was 0.2 Hz. For recording of L-type calcium channel currents the holding potential was $-50 \mathrm{mV}$ to inactivate T-type channels. All recordings were obtained at $22^{\circ} \mathrm{C}$. After patch break the unfiltered transient in response to a pulse from -80 to $-75 \mathrm{mV}$ was recorded and integrated to obtain cell capacitance.

Materials. The (+)enantiomer of $\left[{ }^{3} \mathrm{H}\right] \mathrm{PN} 200-110$ was obtained from New England Nuclear, Boston, MA. ( \pm Bay K 8644 was a gift of Miles Laboratories, West Haven, CT. The unlabeled (+)enantiomer of PN200-1 10 was a gift from Sandoz Ltd., Basel, Switzerland. Propranolol and phentolamine were from Sigma Chemical Company, St. Louis, MO. Dihydropyridines were dissolved in $70 \%$ ethanol at a concentration of $10^{-3} \mathrm{M}$, protected from light, stored a maximum of $3 \mathrm{wk}$, and subsequently diluted in buffer before use. Control experiments confirmed that the low final ethanol concentration by itself had no measurable effect.

Statistical analysis. Contractility and current-voltage curves were compared by analysis of variance (ANOVA). Binding parameters were compared by unpaired $t$ test. Data are expressed throughout as means \pm SEM. A $P$ value of $<0.05$ was chosen to indicate a statistically significant difference.

\section{Results}

Myocyte innervation in vitro. After $3 \mathrm{~d}$ of growth, neonatal rat ventricular myocytes developed a stellate configuration and spontaneously contracted at $103 \pm 1$ contractions/min $(n=60)$. When sympathetic ganglia were co-cultured with the myocytes for the initial $72 \mathrm{~h}$ in culture, axons were readily apparent (Fig. $1, a$ and $b$ ). Individual axons made direct contact with $20-50 \%$ of myocytes in each culture (Fig. $1 \mathrm{c}$ ). Directly innervated myocytes contracted at $125 \pm 4$ contractions/min $(n=55, P$ $<0.001$ ). For some experiments, ganglia were removed and axons permitted to degenerate. $8 \mathrm{~h}$ after ganglia removal, most axons appeared to degenerate; a few remained visible in the cultures (Fig. $1 d$ ). By $24 \mathrm{~h}$ after removal of ganglia, virtually all axons had disappeared (Fig. $1 e$ ). Thus, innervation and dener- 

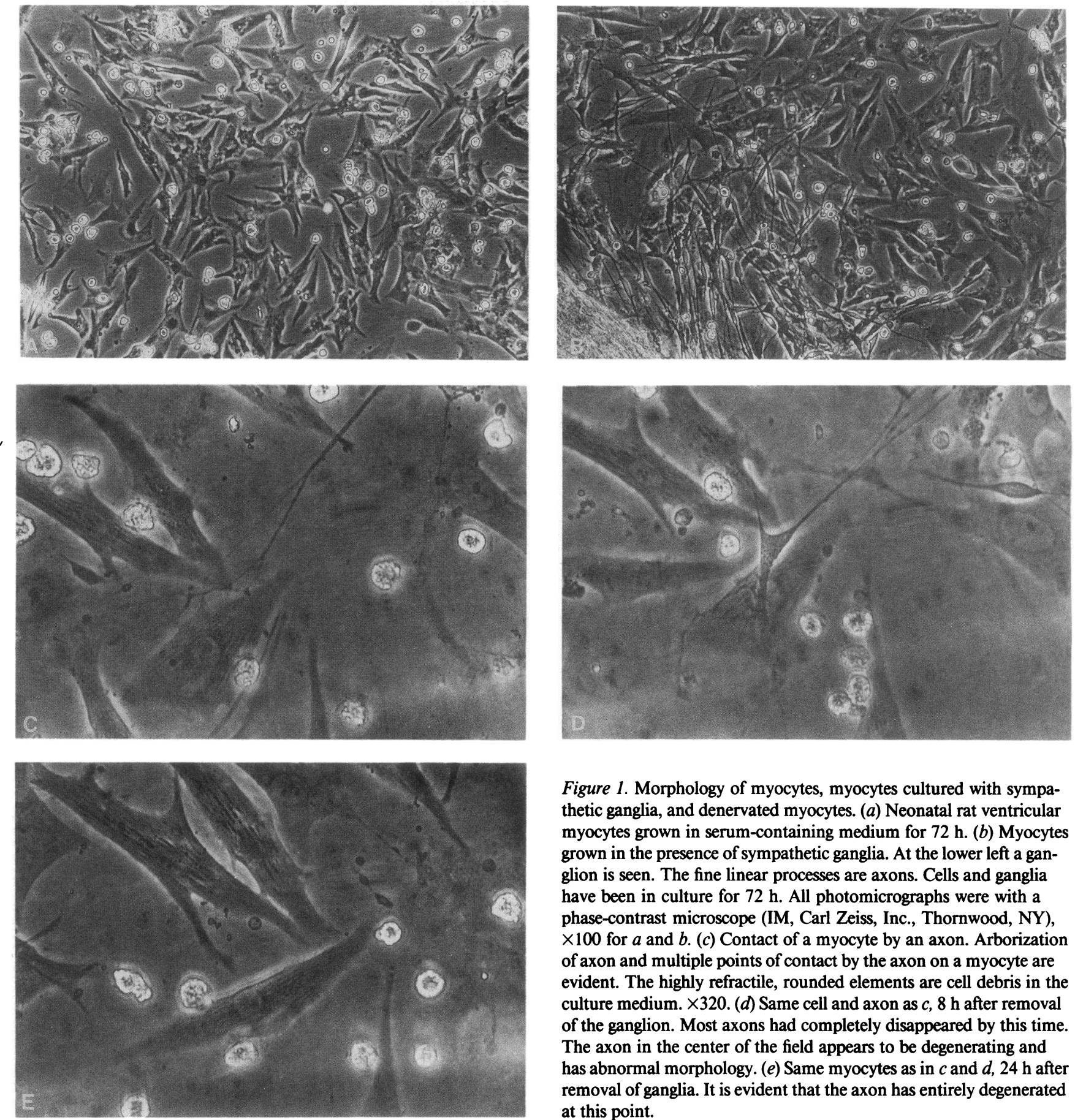

Figure 1. Morphology of myocytes, myocytes cultured with sympathetic ganglia, and denervated myocytes. (a) Neonatal rat ventricular myocytes grown in serum-containing medium for $72 \mathrm{~h}$. (b) Myocytes grown in the presence of sympathetic ganglia. At the lower left a ganglion is seen. The fine linear processes are axons. Cells and ganglia have been in culture for $72 \mathrm{~h}$. All photomicrographs were with a phase-contrast microscope (IM, Carl Zeiss, Inc., Thornwood, NY), $\times 100$ for $a$ and $b$. (c) Contact of a myocyte by an axon. Arborization of axon and multiple points of contact by the axon on a myocyte are evident. The highly refractile, rounded elements are cell debris in the culture medium. $\times 320$. (d) Same cell and axon as $c, 8 \mathrm{~h}$ after removal of the ganglion. Most axons had completely disappeared by this time. The axon in the center of the field appears to be degenerating and has abnormal morphology. (e) Same myocytes as in $c$ and $d, 24 \mathrm{~h}$ after removal of ganglia. It is evident that the axon has entirely degenerated at this point.

vation could be accomplished in vitro by this co-culture approach.

To determine whether true functional innervation could occur between the ganglia and myocytes, a microelectrode was placed adjacent to a ganglion and the motion of an innervated myocyte was tracked. A ganglion was stimulated and as can be seen in Fig. 2, stimulation of a ganglion produced an increased frequency of contraction of the innervated cell, with $1: 1$ coupling. Ganglion-myocyte coupling could be maintained for at least $5 \mathrm{~min}$. If stimulation was stopped for $5 \mathrm{~min}$ then restarted, ganglion-myocyte coupling again was evident. If stimulation was stopped and the cells superfused with $1 \mu \mathrm{M}$ propranolol for

5 min, ganglion-myocyte coupling was abolished in each of seven experiments. However, in the presence of propranolol, even though ganglion stimulation could not produce myocyte contractions, if myocytes were directly stimulated by an electrode placed close to the cell, a contractile response could be easily produced. Thus, it appears likely that there is a stimulatory neurotransmitter (presumably norepinephrine) being released from the axon with physiological response by the myocyte.

Response to $\left[\mathrm{Ca}^{2+}\right]_{0}$ and calcium channel effectors. The contractile responses of three types of myocyte preparations were studied. The first preparation consisted of ventricular myo- 


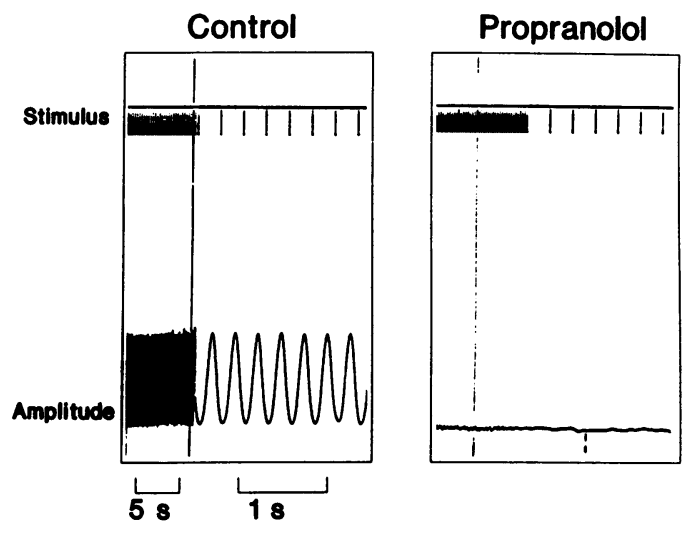

Figure 2. Contractile response of a myocyte to stimulation of a sympathetic ganglion. A sympathetic ganglion was stimulated and contractile amplitude of a myocyte contacted by an axon was recorded. The ganglion was stimulated at $3.5 \mathrm{~Hz}, 2-\mathrm{ms}$ pulse, $5 \mathrm{~V}, 37^{\circ} \mathrm{C}$, Stimulus record (top tracing) and amplitude of contraction of myocyte (lower tracing) are shown. Control indicates response in control physiological buffer. Stimulation and response continued for $5 \mathrm{~min}$, then the stimulator was turned off for $5 \mathrm{~min}$. When stimulation was restarted after $5 \mathrm{~min}$ of rest, myocyte contraction immediately resumed in an identical fashion (not shown). The stimulation was halted and the monolayer was superfused with $1 \mu \mathrm{M}$ propranolol for $5 \mathrm{~min}$, then stimulation was restarted (panel labeled Propranolol). Under these conditions, contractile response was abolished.

cytes cultured for $72 \mathrm{~h}$ in the absence of sympathetic ganglia (control cells). The second preparation consisted of myocytes cultured for $72 \mathrm{~h}$ in the presence of sympathetic ganglia. Specifically, cells that were in contact with the axons were studied (innervated myocytes). The third preparation constituted myocytes on culture dishes where ganglia and myocytes were grown in co-culture. However, the third type of myocyte did not have direct physical contact with an axon. In this way, the environment was identical to that of the directly innervated myocytes, save for direct neuronal contact. These myocytes were therefore considered to be grown in medium "conditioned" by growth of ganglia.

The $\mathrm{pCa}$-contractile amplitude relationship was determined for control myocytes, innervated myocytes, and myocytes grown in conditioned medium (Fig. 3). Myocytes directly innervated showed a significantly greater increase in amplitude of contraction in response to increasing $\left[\mathrm{Ca}^{2+}\right]_{0}$ than did control myocytes or myocytes grown in conditioned medium. With the contractile response in $0.9 \mathrm{mM}\left[\mathrm{Ca}^{2+}\right]_{0}$ taken as control, innervated myocytes increased their amplitude of contraction to $200 \%$ of control in response to increasing $\left[\mathrm{Ca}^{2+}\right]_{0}$, whereas control myocytes increased their amplitude of contraction to only $140 \%$ of control.

There are many potential aspects of excitation-contraction coupling wherein innervation might lead to modulation of the $\mathrm{pCa}$-contractile response relationship. As an approach to determining whether calcium channel function might contribute to the altered response to $\left[\mathrm{Ca}^{2+}\right]_{0}$, the contractile response to the DHP calcium channel agonist Bay K 8644 was determined. Myocytes innervated by sympathetic neurons had a markedly increased response to graded concentrations of Bay K 8644 compared to control myocytes or to myocytes grown in conditioned medium but lacking direct contact by an axon (Fig. $4 a$ ). When the [Bay K 8644]-contractile response relationship was replotted with normalization to $100 \%$ response of each myocyte, curves for the three types of preparations were superimposable (Fig. 4 b), indicating no change in the $\mathrm{EC}_{50}$ for BAY K 8644. These data indicate that sympathetic innervation increases the contractile response to a calcium channel agonist, possibly due to an increase in $\mathrm{L}$ channel calcium current.

In the foregoing studies, myocytes were stimulated to contract by a platinum wire electrode placed close to the myocyte of interest. With this technique there is a possibility that the electrical stimulation of the myocyte could cause norepinephrine release from the nerve terminals near the myocytes, enhancing the contractile responses. To examine this possibility, the response to Bay $\mathrm{K} 8644$ and to elevated $\left[\mathrm{Ca}^{2+}\right]_{0}$ were examined in the presence of propranolol $\left(10^{-6} \mathrm{M}\right)$ to block $\beta$-adrenergic receptors or in the presence of phentolamine $\left(10^{-6} \mathrm{M}\right)$ to block $\alpha$-adrenergic receptors. As can be seen in Fig. 5, $a$ and $b$, $\alpha$ and $\beta$ blockade did not diminish the contractile response to Bay $\mathrm{K}$ 8644, making incidental norepinephrine release unlikely as a mechanism for the enhanced response to Bay $\mathrm{K}$ 8644. The response to $\left[\mathrm{Ca}^{2+}\right]_{0}$ in the presence of $\alpha$ and $\beta$ blockers was also unaffected (data not shown).

The findings described above indicate that sympathetic innervation produced one or more alterations in directly innervated myocytes such that their response to $\left[\mathrm{Ca}^{2+}\right]_{0}$ and to a DHP calcium channel agonist was augmented. Among possible changes produced by innervation are alterations in number or gating of L-type calcium channels, alterations in contractile protein isoforms, or alterations in ion pumps or exchangers such as the $\mathrm{Na}-\mathrm{Ca}$ exchanger, the sarcoplasmic reticulum calcium ATPase, or the sarcolemmal calcium ATPase. To determine if the effect of innervation on Ca channel function persisted after denervation, the ganglia where removed by micro-

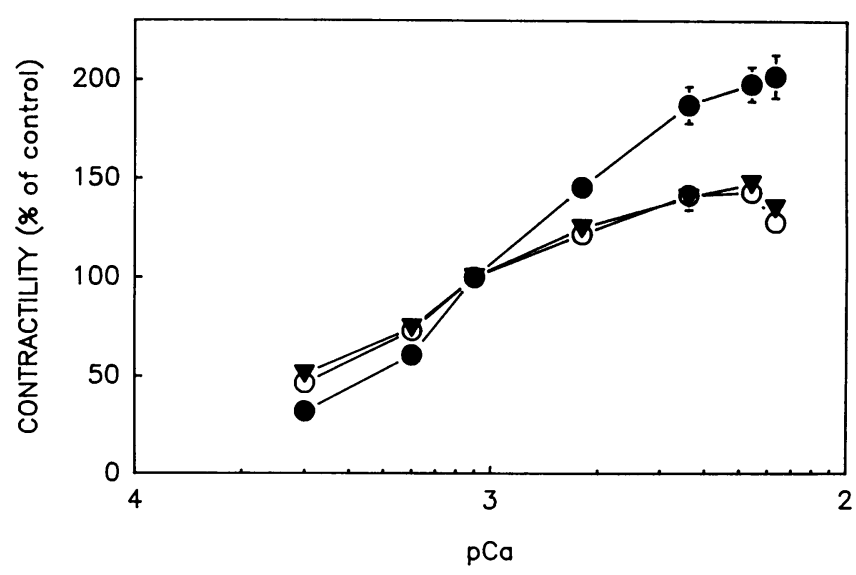

Figure 3. pCa-contractile response relationships. Myocytes were directly stimulated to contract and amplitude of contraction was recorded in response to graded $\left[\mathrm{Ca}^{2+}\right]_{0} .100 \%$ amplitude of contraction was defined as that present in $0.9 \mathrm{mM}\left[\mathrm{Ca}^{2+}\right]_{0}$. (0) Contractile response of control myocytes $(n=8) ;(\bullet)$ contractile response of innervated myocytes $(n=8) ;(\nabla)$ contractile response of myocytes grown in conditioned medium $(n=8)$. Analysis of variance revealed that the curve for the innervated myocytes differed significantly from that of control myocytes $(P<0.05)$. The curve for myocytes grown in conditioned medium was indistinguishable from the curve for control myocytes. Error bars indicate standard errors of the mean. Where error bars are omitted, the error bar is smaller than the symbol. The $\mathrm{EC}_{50}$ for control myocytes was $0.55 \pm 0.05 \mathrm{mM}$ and was $0.92 \pm 0.01$ $\mathrm{mM}$ for innervated myocytes $(P<0.01)$. 

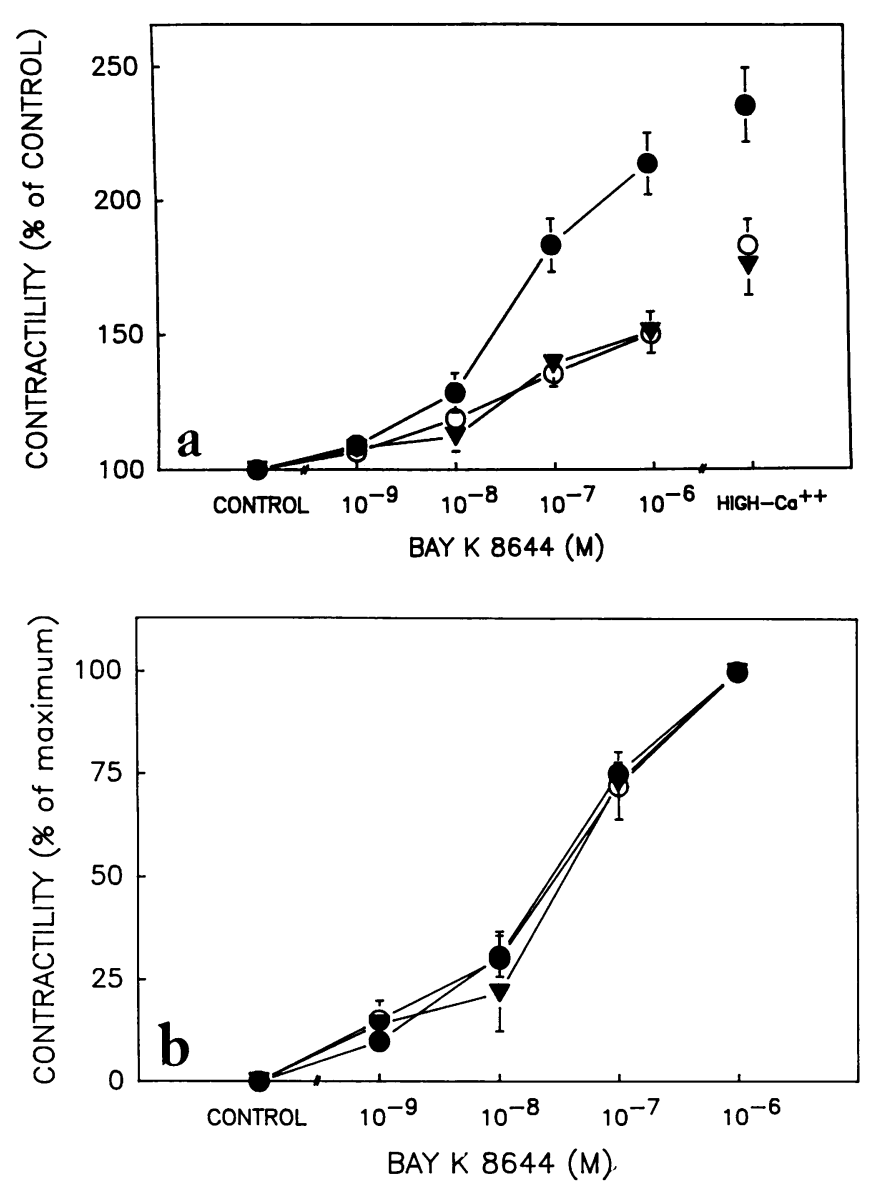

Figure 4. [Bay K 8644]-contractile response relationship. The contractile response to Bay $\mathrm{K} 8644$ was studied in the myocyte preparations. Each preparation was studied in its $\mathrm{EC}_{\mathbf{5 0}}$ concentration of $\left[\mathrm{Ca}^{2+}\right]_{0}$. Ordinate: amplitude of contraction. Control buffer contained no added Bay K 8644. (a) The contractile response to Bay K 8644 for innervated myocytes was significantly greater than that for control myocytes. ANOVA revealed an overall difference between the curves $(P<0.05)$. There is no difference in contractile response between control myocytes and myocytes grown in conditioned medium. The high- $\left[\mathrm{Ca}^{2+}\right]_{0}$ response was the contractile response of each preparation to its $\mathrm{EC}_{100}$ calcium concentration ( $n=10$ for each experiment). ( $\bullet$ ) Innervated myocytes; (o) control myocytes; ( $\boldsymbol{v}$ ) myocytes grown in conditioned medium. (b) Data in Fig. 4a replotted with $100 \%$ defined as the maximum response for each myocyte. The curves are statistically indistinguishable, indicating no change in sensitivity to Bay $\mathrm{K}$ 8644.

dissection and 8 and $24 \mathrm{~h}$ later cells were tested for Ca channel function. $8 \mathrm{~h}$ after ganglia removal, most axons were no longer visible, and those that were visible appeared to be degenerating (Fig. $1 d$ ). When studied $8 \mathrm{~h}$ after removal of ganglia, myocytes that had previously been innervated maintained their robust contractile response to Bay K 8644 and to $\left[\mathrm{Ca}^{2+}\right]_{0}$ (Fig. $6 a$ ).

Cells were maintained in culture for up to $24 \mathrm{~h}$ after denervation. Contractile responses of previously innervated myocytes was again assessed (Fig. 6 b). The contractile response to Bay K 8644 remained augmented and indistinguishable from myocytes that had not undergone denervation. Thus, the factor(s) that account for the enhanced contractile response to extracellular calcium and to a calcium channel agonist subse- quent to innervation appear to turn over slowly and to remain functionally unchanged for at least $24 \mathrm{~h}$ after denervation. Innervation may be producing irreversible commitment of the cell to an altered phenotype that is more highly differentiated. Longer-term observations after sympathetic denervation will be necessary to resolve this possibility.

DHP binding sites. To determine whether sympathetic innervation alters the number of L-type calcium channels as determined by DHP binding, equilibrium binding experiments were performed with the DHP antagonist ligand ${ }^{3} \mathrm{H}(+)-$ PN200-110. Assays were performed on membranes from control myocytes and from myocytes co-cultured with ganglia for $72 \mathrm{~h}$ followed by denervation for $8 \mathrm{~h}$. Denervation was performed before the assay to ensure that DHP binding sites on neurons were not being detected (Fig. 7). PN200-1 10 bound to membranes with a single affinity state and with acceptably low nonspecific binding (nonspecific binding was $<25 \%$ of total at the $K_{\mathrm{D}}$ ); binding was saturable. Computer analysis of equilib-
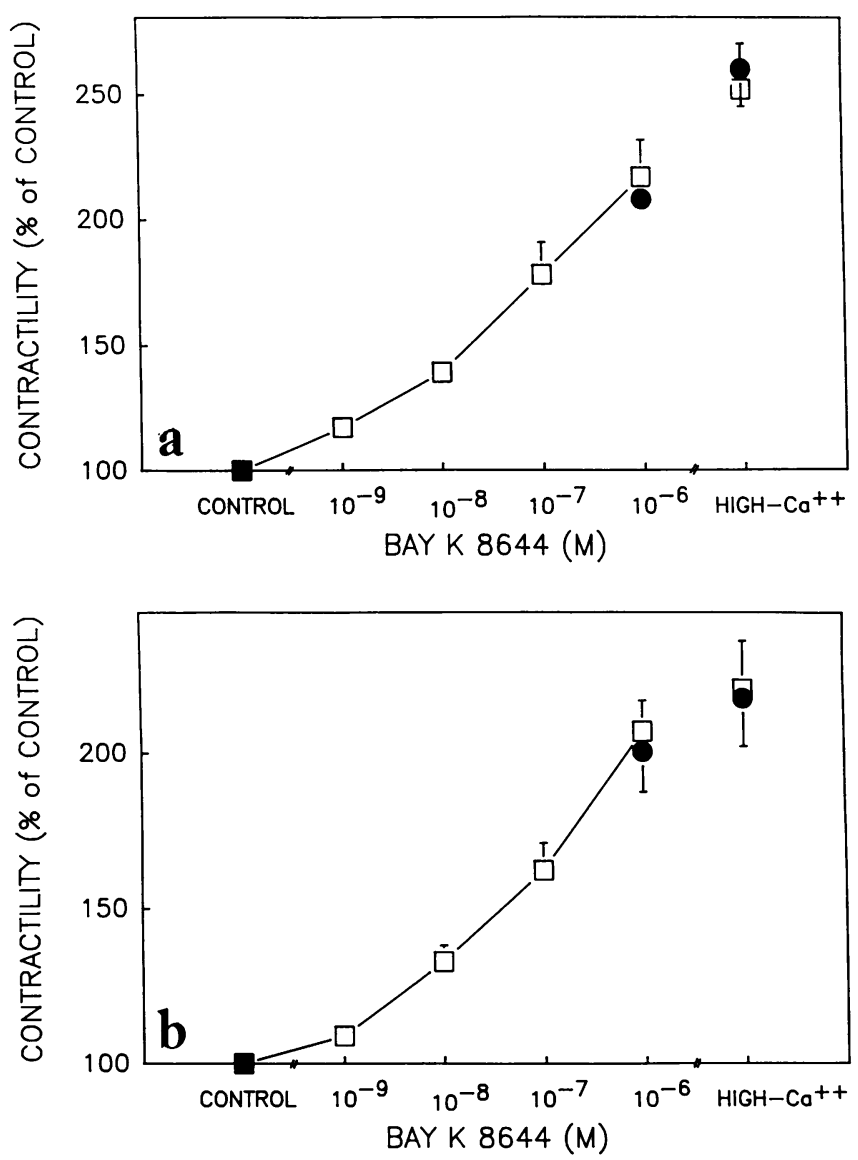

Figure 5. Effect of $\alpha$ and $\beta$ blockade on contractile responses to Bay $\mathrm{K}$ 8644. (a) Contractile response to Bay K 8644 in the presence of $10^{-6}$ $\mathrm{M}$ propranolol is plotted. Drug was superfused $5 \mathrm{~min}$ before the experiment. For comparison, cells from the same culture not exposed to propranolol also had their contractile response measured under control conditions and in response to $10^{-6} \mathrm{M}$ Bay K 8644 and to the $\mathrm{EC}_{100}$ concentration of calcium. Propranolol did not alter the contractile response of innervated myocytes. ( $\square$ ) Presence of propranolol $(n=5) ;(\bullet)$ absence of propranolol $(n=4)$. (b) The protocol was the same as in $a$, except that the $\alpha$-adrenergic blocker phentolamine was present. The $\alpha$ blockade did not alter the response to Bay K 8644 for innervated myocytes. ( $\square$ ) Presence of phentolamine $(n=4)$; ( $\bullet$ absence of phentolamine $(n=4)$. 

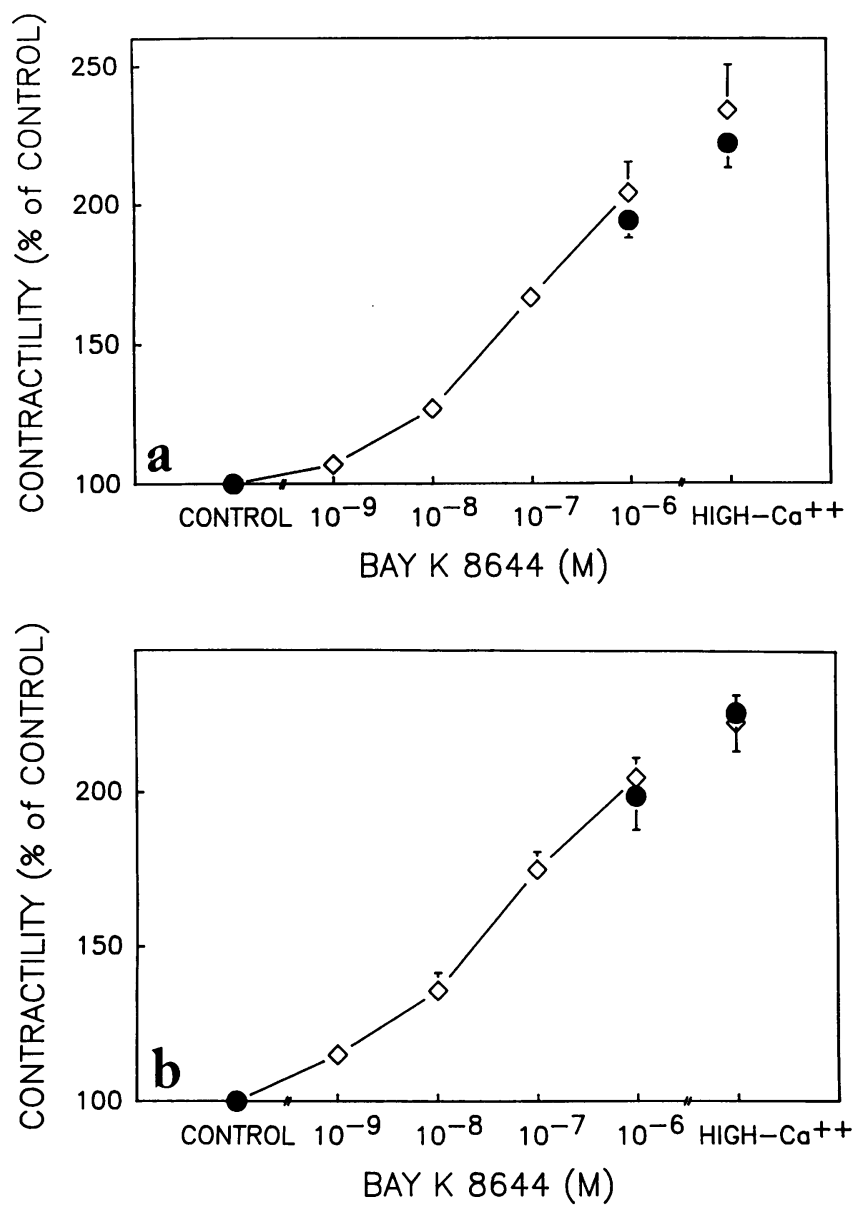

Figure 6. Effect of denervation on contractile responses to Bay $\mathrm{K}$ 8644. (a) $8 \mathrm{~h}$ after denervation, the contractile response to Bay K 8644 was determined and compared to that of myocytes that had not undergone denervation. ( () Denervated myocytes $(n=4) ;(\bullet)$ innervated myocytes $(n=4)$. (b) Contractile response to Bay K $864424 \mathrm{~h}$ after denervation. $(\diamond)$ Denervated myocytes $(n=6)(\bullet)$ innervated myocytes $(n=6)$. Denervation did not alter the contractile response to Bay K 8644 either at 8 or $24 \mathrm{~h}$.

rium binding isotherms indicated that a single affinity state for the DHP antagonist was present. Goodness-of-fit of binding data to a two-site model was compared to fit to a one-site model. In no case did the two-site model offer a better fit than the single-site model $(F$ test, $P>0.05)$. When computer-derived binding parameters for control myocytes and innervated myocytes were compared, no difference in $K_{\mathrm{D}}$ was found, but a significant difference in the number of DHP binding sites was evident (Table I). Control membranes had $51 \pm 5 \mathrm{fmol} / \mathrm{mg}$ protein PN200-1 10 binding sites whereas membranes from innervated myocytes had $108 \pm 20 \mathrm{fmol} / \mathrm{mg}$ protein binding sites $(P$ $<0.01$ ). Thus, concordant with the increased physiologic response to a calcium channel agonist, there was a twofold increase in the number of DHP binding sites on innervated myocytes compared with control cells.

Whole-cell voltage clamp data. Control myocytes and myocytes in direct contact with a sympathetic neuron were studied in the whole cell voltage clamp configuration. The L-type channel current carried by $\mathrm{Ba}^{2+}$ at $-50 \mathrm{mV}$ holding potential with -40 to $+50-\mathrm{mV}$ test potentials was recorded. Current density-voltage $(I-V)$ curves were determined for control myo- cytes, innervated myocytes and myocytes grown in conditioned medium. Calcium currents were measured as peak inward current in response to zero current. As an index of current density, we used cell current divided by cell capacitance (picoamperes per picofarad) to correct for variance in cell size. Care was taken to study single myocytes that were not in contact with other myocytes. Compared to control myocytes, innervated myocytes showed a significantly greater peak current density (Fig. 8). The peak of the $I-V$ curve was shifted slightly, from $0 \mathrm{mV}$ for control myocytes to $-10 \mathrm{mV}$ for innervated myocytes. The $I-V$ curve for myocytes grown in conditioned medium was indistinguishable from that for control myocytes. The current density of L-type calcium channels is summarized in Fig. $8 c$. On average, the current density at $V_{\mathrm{m}}=-10 \mathrm{mV}$ for innervated myocytes was $10.5 \pm 0.4 \mathrm{pA} / \mathrm{pF}$, whereas for control myocytes it was $4.5 \pm 0.4 \mathrm{pA} / \mathrm{pF}(P<0.01)$. Inactivation of L-type calcium currents was investigated (Fig. 9). There was a significant difference in voltage for half-inactivation of current from innervated and control myocytes $(P<0.01)$. Cells grown in conditioned medium were indistinguishable from noninnervated cells. Thus, at a given holding potential the innervated myocytes had more calcium channels available for activation.

\section{Discussion}

The principal finding of this study is that physical contact between a sympathetic neuron and ventricular myocytes in vitro produced increased expression of functional L-type calcium channels. This direct physical contact by a sympathetic nerve axon (physical innervation) appears to be essential; cells grown in medium conditioned by growth of myocytes and sympathetic ganglia did not demonstrate increased expression of $\mathrm{L}$ type calcium channels.

There are three lines of evidence to support the conclusion that innervation increased L-type calcium channel expression. First, innervated myocytes showed a markedly increased contractile response to $\left[\mathrm{Ca}^{2+}\right]_{0}$. While this effect is consistent with increased calcium channel expression and an increase in calcium channel-dependent calcium flux leading to greater re-

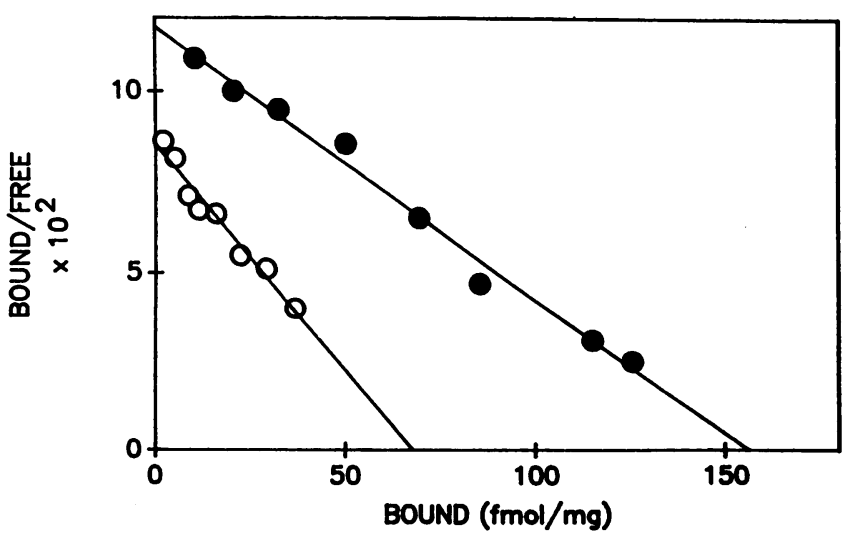

Figure 7. $\left[{ }^{3} \mathrm{H}\right](+)-\mathrm{PN} 200-110$ binding. Computer-derived Scatchard plot of $\left[{ }^{3} \mathrm{H}\right](+)-P N 200-110$ binding to cell membranes for representative experiments. [Bound ligand] is indicated on the abscissa and bound/free is indicated on the ordinate. (๑) Membranes from innervated myocytes $\left(K_{\mathrm{D}}=124 \mathrm{pM}, B_{\max }=69 \mathrm{fmol} / \mathrm{mg}\right.$ protein); (0) membranes from control myocytes $\left(K_{\mathrm{D}}=156 \mathrm{pM}, B_{\max }=157 \mathrm{fmol} /\right.$ mg protein). 
Table I. $\left[{ }^{3} \mathrm{H}\right](+)$ PN200-110 Binding Parameters

\begin{tabular}{lccc}
\hline & $n$ & $K_{\mathrm{D}}$ & $B_{\max }$ \\
\hline & & $p M$ & fmol/mg protein \\
Control myocytes & 8 & $138.9 \pm 15.9$ & $51.2 \pm 5.4$ \\
Innervated myocytes* & 5 & $145.0 \pm 12.7$ & $108.0 \pm 20.1^{\ddagger}$
\end{tabular}

* Innervated myocytes underwent denervation $8 \mathrm{~h}$ before ligand binding experiments.

${ }^{\ddagger} P<0.01$ compared to control myocytes.

lease of calcium from the sarcoplasmic reticulum, other mechanisms in innervated myocytes are also possible. Indeed, there is no reason to suspect that innervation would alter calcium channel abundance or function without other effects on the cell. Therefore, a more specific probe of L-type calcium channel function was utilized, the DHP calcium channel agonist Bay K 8644. This ligand specifically interacts with the L-type calcium channel, favors a more prolonged open state of the channel, and increases the inward calcium current (12). Innervated myocytes demonstrated a markedly increased maximal contractile response to this specific calcium channel agonist, with no change in sensitivity. These findings support the view

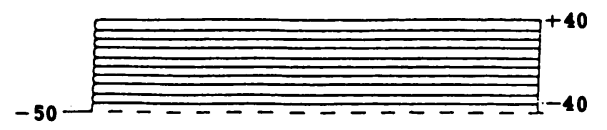

1

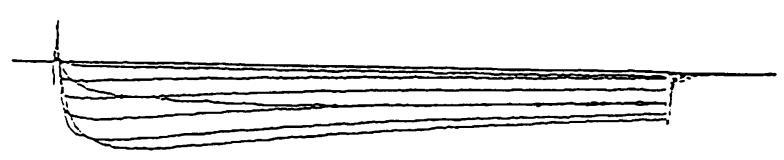

2

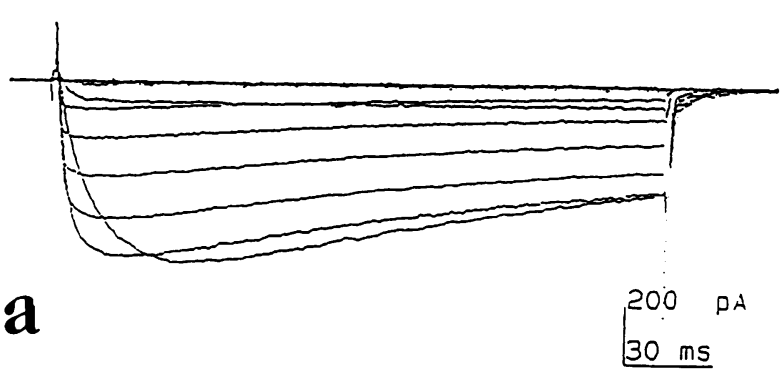

that L-type calcium channel abundance increased after innervation with no structural change in the ligand-binding domain of the $\alpha_{1}$ subunit that might affect ligand affinity. We did not observe a change in sensitivity to Bay K 8644 in innervated cells. With an effector-response system as complex as ligand binding to a channel altering excitation-contraction coupling, it is not possible to predict a priori how concentration-effect curves may shift (13). Moreover, it is distinctly possible that more than one component of the excitation-contraction coupling pathway is altered by innervation.

Second, to test more directly the hypothesis that innervation produced an increase in expression of L-type calcium channels, ligand binding studies were conducted. Membranes from myocytes grown in the presence of ganglia showed a twofold increase in DHP binding sites compared to controls. There was no change in $K_{\mathrm{D}}$ for dihydropyridine binding consistent with no change in $\mathrm{EC}_{50}$ for $\mathrm{BAY} \mathrm{K} 8644$ contractile response. Quantitation of the increase in DHP binding sites is subject to certain limitations. First, axons made direct contact with only $20-50 \%$ of the cells in a culture plate. Thus, if direct contact was necessary to produce an increase in calcium channel $\alpha_{1}$ subunit expression, the directly contacted cells might have a much greater increase in DHP binding site number than that determined by assaying the entire population of cells. Typically, each innervated myocyte appears to be coupled physi-
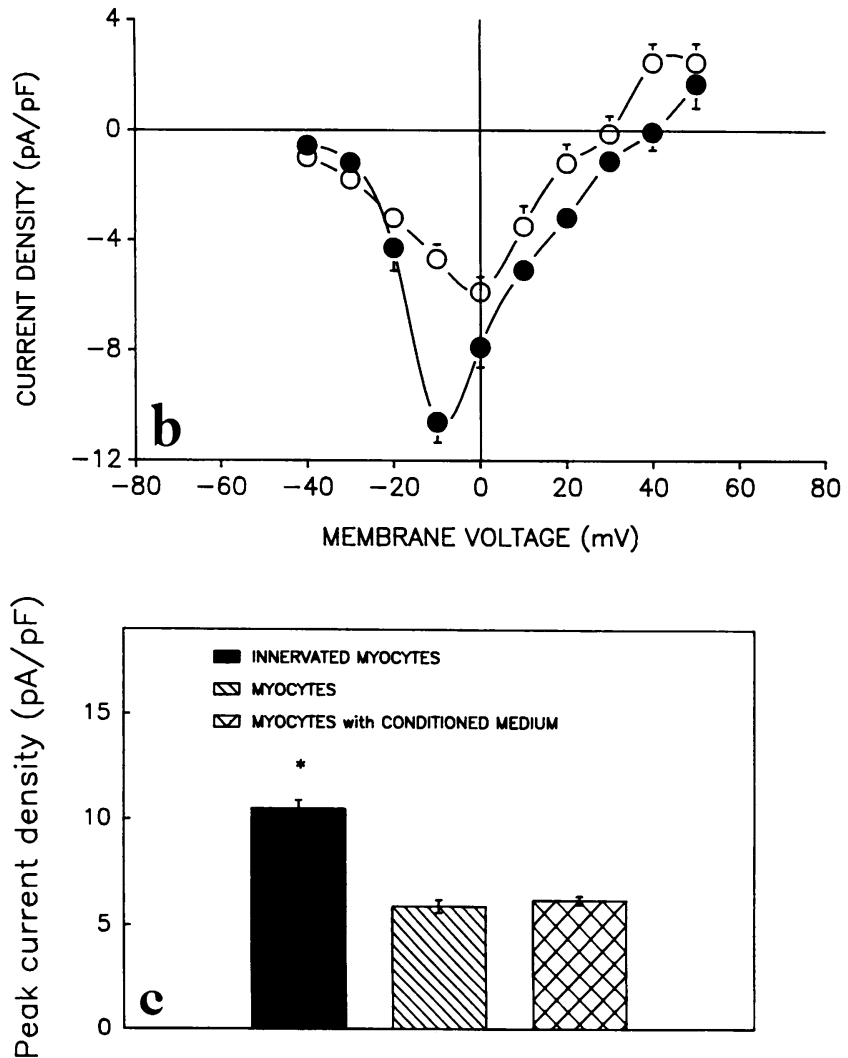

Figure 8. I-V relationship of L-type calcium channels. (a) Current tracing for representative control and innervated myocytes. Membrane potential was stepped from holding potential of $-50 \mathrm{mV}$ to indicated step potential. Duration of step not to scale. Panel 1 shows current tracings for a control myocyte; panel 2 for an innervated myocyte. $(b)$ The $I-V$ curve for control myocytes is shown in open circles $(n=8)$, and for innervated myocytes in filled circles $(n=5)$. Myocytes were selected for study that were not in contact with other myocytes. (c) Peak current density of L-type calcium channels. The peak current density for innervated myocytes is shown in the closed bar, for control myocytes in the hatched bar, and for myocytes grown in conditioned medium in the cross-hatched bar. The $n$ values are as in $b$. The current density was significantly greater for innervated myocytes than for control myocytes $(P<0.01)$. 


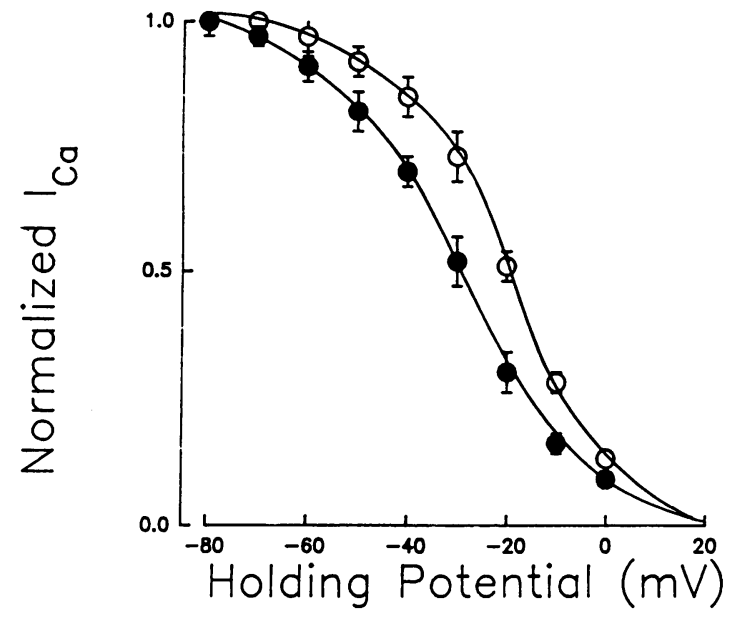

Figure 9. Inactivation of L-type calcium current. Inactivation of Ltype calcium current was studied for noninnervated cells $(0)$ and innervated cells $(\bullet)$ by measuring $\mathrm{Ca}^{2+}$-activated current at $+20 \mathrm{mV}$ from various holding potentials. The $\mathrm{Ca}^{2+}$ current was normalized to peak current elicited from a holding potential of $-80 \mathrm{mV}$. The results were plotted against holding potential and fitted to the Boltzmann equation. At a given membrane potential, more L-type calcium channels were available for activation in control than in innervated myocytes. For innervated myocytes, current was half inactivated at $-31.2 \pm 2.1 \mathrm{mV}$, compared with $-23.7 \pm 0.9 \mathrm{mV}(P<0.01)$ for noninnervated myocytes.

cally and electrically with two to three adjacent myocytes. If the factor(s) that lead to increased calcium channel expression cross gap junctions, it is possible that not only the directly contacted myocyte but closely coupled myocytes as well might demonstrate an increase in calcium channel expression. Thus, it is likely that the twofold increase in DHP binding sites observed is a minimal estimate for the increase in DHP receptors on a cell that is directly innervated. We consider it unlikely that ligand binding studies were confounded by the presence of $L$ type calcium channels on residual neural elements. Cultures underwent removal of ganglia $8 \mathrm{~h}$ before to preparation of membranes. By 8 hours, axons were almost entirely absent or degenerated.

The third line of evidence supporting the postulate that direct innervation increases L-type calcium channel expression is derived from the whole-cell voltage clamp recordings. For these experiments, only single myocytes that were not contacting other cells save for the sympathetic nerve axon were studied. Calcium channel current density was clearly increased in the single, innervated myocytes. That $I-V$ curves were being recorded from L-type calcium channels was confirmed by typical voltage dependence and sensitivity to Bay K 8644 (12). There was a small shift to the left of the voltage for peak inward current for innervated cells. The biological importance of this shift and the underlying mechanism remain to be determined. It is possible that innervation may alter either sarcoplasmic reticulum function or $\left[\mathrm{Ca}^{2+}\right]_{i}$, either of which Cohen and Lederer (14) have shown can alter $I_{\mathrm{Ca}}$.

Taken together, these three sets of experiments demonstrate that direct sympathetic innervation increases expression of functional L-type calcium channels. Evidence is now convincing that the DHP receptor domain is within the $\alpha_{1}$ subunit of the L-type calcium channel (15), so that ligand binding stud- ies with a DHP ligand and patch clamp studies provide complementary data on the same structures.

The model system for the in vitro innervation experiments deserves comment $(2,7,16)$. Ventricular myocytes were cultured from 1-d postnatal rat hearts. Although autonomic neurons are present in the rat heart during embryonic cardiac organogenesis, functional innervation does not develop until after birth (17). Functional adrenergic transmission in the rat heart can be detected consistently $1 \mathrm{~d}$ after birth, but development of mature adrenergic innervation is further delayed until $21 \mathrm{~d}$ after gestation (17). Thus, the studies reported here were conducted on myocytes that had at most a brief exposure to sympathetic neurotransmitters in vivo.

A possible confounding factor for in vitro innervation studies is that upon prolonged tissue culture, rat sympathetic neurons are known to develop the ability to synthesize and accumulate acetylcholine and lose their ability to synthesize norepinephrine (18). However, it takes 2-4 wk in vitro for the transition from sympathetic to parasympathetic properties to occur. Our studies were conducted at $72-96 \mathrm{~h}$ in vitro, making this effect unlikely. Moreover, we were able to demonstrate (Fig. 2) that stimulation of ganglia produced an increase in frequency of contraction that is a typical sympathetic neurotransmitter response.

While it is evident that co-culture of sympathetic ganglia with myocytes produces physical association (Fig. 1), with a concomitant change in spontaneous beating rate and an increase in calcium channel expression and function, we cannot be absolutely certain in this in vitro system functional sympathetic neuroeffector transmission has been achieved. Clearly neuron-myocyte contact produces important changes in the myocyte. The responsible effector(s) are being sought.

A distinct advantage of the neuron-myocyte co-culture system is that the response of specific myocytes could be determined after innervation or denervation. In the intact ventricle, myocytes comprise a numerical minority of cells, so that ligand binding studies or physiologic studies reflect the responses of neural, vascular, and connective tissue elements as well as ventricular myocytes. In vitro sympathetic innervation models have been reported by several laboratories $(7,16,19)$. A particular advantage of our approach using relatively large ganglia rather than finely minced neural tissue in culture is that it permits the examination of denervation in vitro by allowing removal or degradation of virtually all neural tissue (2).

An additional important finding of this study is that after denervation for at least $24 \mathrm{~h}$, an increase in functional L-type calcium channels can still be found. Although the available data do not permit conclusions regarding the mechanisms by which the sustained increase in calcium channel number occurs, possibilities include innervation increasing transcription rates for genes for one or more of the five subunits of the L-type calcium channel.

Sympathetic innervation of myocytes produced alterations in contractile properties that are not readily explained by an increase in number of L-type calcium channels alone. Innervation was associated with a small but definite decline in contractile sensitivity to $\left[\mathrm{Ca}^{2+}\right]_{0}$. One possible explanation is that innervation alters the expression of several genes in a pattern similar to that which occurs during maturation. We previously reported (5) that in the developing chick heart there is a decrease in contractile sensitivity to $\left[\mathrm{Ca}^{2+}\right]_{0}$, and other changes in structures modulating calcium homeostasis have been reported 
with innervation and/or development $(8,20-22)$. Thus, innervation-induced events analogous to those occurring during normal maturation of neonatal myocytes is a unifying hypothesis that might explain many of these observations $(23,24)$.

It is of note that myocytes grown in conditioned medium did not demonstrate increased numbers of functional calcium channels. Direct contact by a sympathetic neuron appears to be required for this effect. This observation suggests that the trophic influence of the neural element is confined to the cell(s) in contact with it, or that the factor(s) released by the sympathetic nerve does not diffuse beyond the synaptic cleft into the culture medium in concentrations sufficient to produce a trophic effect on other myocytes. What signal might be produced by direct contact with the sympathetic nerve to produce increased expression of L-type calcium channels? Neurotransmitter(s) that induce differentiation $(22,25-27)$ or that might alter Gprotein expression $(2,19,28)$ are strong candidates. Given the alterations in contractile properties of innervated myocytes, it is unlikely that the signal produced by innervation only alters L-type calcium channel expression; rather it is more likely that the signaling process has a broader effect on the cells' genetic program. The dependence of $\mathrm{Ca}$ channel induction on very close association or direct contact between nerve and muscle suggests a paracrine mechanism of growth factor induction or interaction of membrane-bound components of the muscle and nerve $(29,30)$. There was a $21 \%$ difference in spontaneous rate of contraction of control and directly innervated myocytes. This might produce a change in rate of deformation of the cell membrane or in cytosolic ion concentrations that could conceivably contribute to alteration in abundance of calcium channels as well. Additional studies will be necessary to discern the effect of beating rate alone on expression of functional ion channels.

In conclusion, sympathetic innervation in vitro of previously uninnervated neonatal rat ventricular myocytes produces an increase in expression of functional L-type calcium channels as judged by ligand binding and electrophysiological and contractile response criteria. Subsequent denervation does not reduce calcium channel number to control levels for at least $24 \mathrm{~h}$. The experimental findings, taken together, are consistent with the hypothesis that sympathetic innervation induces changes in cultured neonatal rat ventricular myocytes analogous to those that occur during normal maturation.

\section{Acknowledgments}

We are grateful to Ms. Michelle Somers for excellent secretarial assistance.

This study was supported in part by grants HL35781 and HL36141 from the National Institutes of Health.

\section{References}

1. Takahashi, M., M. J. Seagar, J. F. Jones, B. F. Reber, and W. Catterall 1987. Subunit structure of dihydropyridine-sensitive calcium channels from skeletal muscle. Proc. Natl. Acad. Sci. USA. 84:5478-5482.

2. Barnett, J. V., and J. B. Galper. 1988. Co-culture of embryonic chick atrial cells and ciliary ganglia enhances parasympathetic responsiveness. Pharmacologist. 3:A100.

3. Reuter, H. 1983. Calcium channel modulation by neurotransmitters, enzymes and drugs. Nature (Lond.). 301:569-573.

4. Curtis, B. M., and W. A. Catterall. 1985. Phosphorylation of the calcium antagonist receptor of the voltage-sensitive calcium channel by cAMP-dependent protein kinase. Proc. Natl. Acad. Sci. USA. 82:2528-2532.

5. Marsh, J. D., and P. D. Allen. 1989. Developmental regulation of cardiac calcium channels and contractile sensitivity to $\left[\mathrm{Ca}^{2+}\right]_{0} . A m$. J. Physiol. 256:H179-H185.

6. Offord, J., and W. A. Catterall. 1989. Electrical activity, cAMP and cytosolic calcium regulate mRNA encoding sodium channel $\alpha$ subunit in rat muscle cells. Neuron. 2:1447-1452.

7. Atkins, D. L., and W. J. Marvin. 1989. Chronotropic responsiveness of developing sinoatrial and ventricular rat myocytes to autonomic agonists following adrenergic and cholinergic innervation in vitro. Circ. Res. 64:1051-1062.

8. Borzak, S., S. Murphy, and J. D. Marsh. 1991. Mechanism of the staircase in rat ventricular cells. Am. J. Physiol. 260:H884-H892.

9. Marsh, J. D., W. H. Barry, and T. W. Smith. 1982. Desensitization to the inotropic effect of isoproterenol in cultured chick ventricular cells. J. Pharmacol. Exp. Ther. 223:60-67.

10. Lee, J. A., and D. G. Allen. 1989. Comparison of the effect of inotropic interventions on isometric tension and shortening in isolated ventricular muscle. Cardiovasc. Res. 23:748-755.

11. Marsh, J. D. 1989. Coregulation of calcium channels and beta-adrenergic receptors in cultured chick embryo ventricular cells. J. Clin. Invest. 84:817-823.

12. Hess, P., J. B. Lansman, and R. W. Tsien. 1984. Different modes of Ca channel gating behavior favored by dihydropyridine $\mathrm{Ca}$ agonist and antagonist. Nature (Lond.). 311:538-544.

13. Strickland, S., and J. N. Loeb. 1981. Obligatory separation of hormone binding and biological response curves in systems dependent upon secondary mediators of hormone action. Proc. Natl. Acad. Sci. USA. 78:1366-1370.

14. Cohen, N. M., and W. J. Lederer. 1988. Changes in the calcium current of rat heart ventricular myocytes during development. J. Physiol. (Lond.). 406:115146.

15. Mikami, A., K. Imoto, T. Tanabe, T. Niidome, Y. Mori, H. Takeshima, S. Narumiya, and S. Numa. 1989. Primary structure and functional expression of the cardiac dihydropyridine-sensitive calcium channel. Nature (Lond.). 340:230 233.

16. Marvin, W. J., D. L. Atkins, V. L. Chittick, and R. K. Hermsmeyer. 1984. In vitro adrenergic and cholinergic innervation of the developing rat myocyte. Circ. Res. 55:49-58.

17. Pappano, A. 1977. Ontogenetic development of autonomic neuroeffector transmission and transmitter reactivity in embryonic and fetal hearts. Pharmacol. Rev. 29:3-33.

18. Patterson, P. H., and L. L. Y. Chun. 1977. The induction of acetylcholine synthesis in primary cultures of dissociated rat sympathetic neurons. Dev. Biol. $60: 473-481$.

19. Steinberg, S. F., E. D. Drugge, J. P. Bilezikian, and R. B. Robinson. 1988. Acquisition by innervated cardiac myocytes of pertussis toxin-specific regulatory protein linked to the $\alpha_{1}$-receptor. Science (Wash. DC). 230:186-188.

20. Fabiato, A., and A. Fabiato. 1978. Calcium-induced release of calcium from the sarcoplasmic reticulum of skinned cells from adult human, dog, cat, rabbit, rat, and frog heart and from fetal and newborn rat ventricle. Ann. NY Acad. Sci. 307:491-522.

21. Vetter, F., H. Will, I. Kuttner, C. Kemsies, and L. Will-Shahab. 1986 Developmental changes of $\mathrm{Ca}^{2+}$ transport system in chick heart. Biomed. Biochim. Acta. 45:S219-S222.

22. Caffrey, J. M., A. M. Brown, and M. D. Schneider. 1987. Mitogens and oncogenes can block the induction of specific voltage-gated ion channels. Science (Wash. DC). 236:570-573.

23. Toyota, N., and Y. Shimada. 1983. Isoform variants of troponin in skeletal and cardiac muscle cells cultured with and without nerves. Cell. 33:297-304.

24. Wieczorek, D. F. 1988. Regulation of alternatively spliced $\alpha$-tropomyosin gene expression by nerve extract. J. Biol. Chem. 263:10456-10463.

25. Rampe, D., J. M. Caffrey, M. D. Schneider, and A. M. Brown. 1988. Control of expression of the 1,4-dihydropyridine receptor in $\mathrm{BC} 3 \mathrm{H} 1$ cell. Biochem. Biophys. Res. Commun. 152:769-775.

26. Varadi, G., Orlowski, and A. Schwartz. 1989. Developmental regulation of expression of the $\alpha_{1}$ and $\alpha_{2}$ subunit mRNAs of the voltage-dependent calcium channel in a differentiating myogenic cell line. FEBS (Fed. Eur. Biochem. Soc.) Lett. 250:515-518.

27. DeLorme, E. M., C. S. Rabe, and R. McGee. 1988. Regulation of the number of functional voltage sensitive Ca channels on PC12 cells by chronic changes in membrane potential. J. Pharmacol. Exp. Ther. 838-843.

28. Yatani, A., and A. M. Brown. 1989. Rapid $\beta$-adrenergic modulation of cardiac calcium channel current by a fast $\mathrm{G}$ protein pathway. Science (Wash. DC). 245:71-74

29. Callewaert, G., I. Hanbauer, and M. Morad. 1989. Modulation of calcium channel in cardiac and neuronal cells by an endogeneous peptide. Science (Wash. DC). 243:663-666.

30. Massague, J. 1990. Transforming growth factor- $\alpha$. A model for membrane-anchored growth factors. J. Biol. Chem. 265:21393-21396. 